\title{
Study Title-Based Framing Effects on Reports of Sexual Violence Factors in College Students
}

\author{
RaeAnn E. Anderson \\ University of North Dakota, raeann.anderson@UND.edu \\ Emily M. Carstens Namie \\ Paige K. Michael \\ Douglas L. Delahanty
}

\section{How does access to this work benefit you? Let us know!}

Follow this and additional works at: https://commons.und.edu/psych-fac

Part of the Psychology Commons

\section{Recommended Citation}

RaeAnn E. Anderson, Emily M. Carstens Namie, Paige K. Michael, et al.. "Study Title-Based Framing Effects on Reports of Sexual Violence Factors in College Students" (2021). Psychology Faculty Publications. 42.

https://commons.und.edu/psych-fac/42

This Article is brought to you for free and open access by the Department of Psychology at UND Scholarly Commons. It has been accepted for inclusion in Psychology Faculty Publications by an authorized administrator of UND Scholarly Commons. For more information, please contact und.commons@library.und.edu. 


\title{
Study Title-Based Framing Effects on Reports of Sexual Violence Factors in College Students
}

Journal of Interpersonal Violence 8862605211016349

8862605211016349

(C) Anderson, R. E., Namie, E. M. C., Micael, P. K., \& Delahanty, D.L. 202। DOI: I0.II77/088626052II0I6349

This is not the version of record, see above.

\section{RaeAnn E. Anderson',2, Emily M. Carstens Namie', Paige K. Michael', and Douglas L. Delahanty'}

\begin{abstract}
Objective: There are many methodological issues in studying sexual violence, including potential framing effects. Framing effects refer to how researchers communicate the purpose of a study to participants, such as, how the study is advertised or explained. The aim of the current study was to investigate if framing effects were associated with differences in participants' self-reported experiences of sexual violence and related correlates. Methods: College students $(N=782)$ were recruited to participate in one of four identical studies that differed in the title: "Questionnaires about Alcohol," "Questionnaires about Crime," "Questionnaires about Health," or "Questionnaires about Sexual Assault." Participants chose one of the four studies and completed measures of sexual violence as well as attitudinal and behavioral measures in randomized order. Results: We found significantly more reports of childhood sexual abuse $(33.6 \%$ vs. $18.5 \%)$, rape (33.9\% vs. $21.1 \%)$, higher frequency of victimization ( $M=1 \mathrm{I} .35$ vs. 5.44$)$, and greater acknowledged rape for bisexual people $(46.2 \%$ vs. $0.0 \%)$ in the Sexual Assault condition compared to other conditions. There were no differences in sexual violence perpetration or attitudinal or behavioral measures. Conclusion: These results revealed that framing effects, based on the study title, affect outcomes in sexual victimization research. Rape was reported 1.6x more in the "Sexual Assault" condition than in the "Health" condition. It is unclear whether these framing effects reflect self-selection bias or framing related increased reports in the Sexual Assault condition, suppression of reports in other conditions, or a combination thereof.
\end{abstract}

\section{Keywords}

sexual violence, sexual assault, sexual violence measurement, methodology, framing effects

\footnotetext{
' University of North Dakota, Psychology, 50 I N. Columbia Road, Grand Forks, ND 5820I

${ }^{2}$ Kent State University, Psychological Sciences, I44 Hilltop Drive, Kent, OH 4422 I
}

\section{Corresponding Author:}

RaeAnn E. Anderson, University of North Dakota, Department of Psychology, 50I N. Columbia Road, Grand Forks, ND 58202-8380, USA. Email: raeann.anderson@UND.edu 
Sexual violence victimization affects approximately one in four college women and is associated with a range of deleterious health consequences (Koss, 1993; Muehlenhard et al., 2017). Framing effects, or the way researchers communicate the topic and purpose of a survey or study (Galesic \& Tourangeau, 2007), may affect reported rates of sexual violence and related risk factors (Koss et al., 2007). Sexual violence is highly stigmatized and an under-reported crime (Kennedy \& Prock, 2018; Wolitzky-Taylor et al., 2011); the way a study is framed may influence how participants disclose, perceive, and label their experiences. For example, Kivivuori et al. (2012) found reports of intimate partner violence increased in frames that were similar to existing violence stereotypes (men harming women) compared to those that were inconsistent (men harming men). Framing has both practical and ethical implications for how researchers should recruit participants for sexual violence studies. Thus, we conducted four parallel, quasi-experimental studies to investigate how study title-based framing effects may impact reported rates of sexual violence victimization, sexual violence perpetration, and attitudinal and behavioral risk factors.

\section{Terms Used}

Hamby (2017) noted that violence terms are often not clearly defined, and varying terms are used interchangeably in violence research. Thus, we define sexual violence as any experience of sexual contact without consent (Basile et al., 2014). We chose to use the phrase "sexual violence" as an umbrella term to encompass the entire range of experiences of sexual contact without consent, consistent with the Centers for Disease Control and the World Health Organization (Basile et al., 2014). Since sexual violence involves more than one person, incidents can be examined from the perspective of the person harmed (i.e., victim/survivor, target) or the person who instigated the incident (i.e., the perpetrator/offender). For clarity, we use the term victimization to refer to the experiences of those who have been harmed by sexual violence. In contrast, perpetration refers to the experiences of those who have harmed others sexually. Framing is the context in which research occurs and can be communicated through the study title, recruitment materials, informed consent.

\section{Self-Selection Bias}

The current study focuses on framing, although with a quasi-experimental design, framing is confounded with self-selection bias; the only way to disarticulate this confound would be full random assignment to study title (i.e., study framing) with minimal if any informed consent as to the topic of the study to deter framing. There are well documented self-selection effects in sexuality research; women are more likely to volunteer for sex-related studies than men (Senn \& Desmaris, 2001). And those who volunteer for sex studies tend to be more sexually experienced and have less conservative attitudes (Saunders et al., 1985). However, attitudes regarding sexual behavior and rape are conceptually distinct (though related, Ryan, 2011).

Specific to violence, research has found little evidence that rates of sexual victimization are related to self-selection bias. Specifically, in one natural quasi-experiment, one condition learned of the study regarding "sexual and interpersonal experiences, mental health, and other events..." during the initial recruitment email. In contrast, the second sample was recruited using a random, unrelated study title and no information on the topic until consent (Rosenthal \& Freyd, 2018). There was no difference in victimization rates (Rosenthal \& Freyd, 2018). Similarly, a Swedish population study found differences in prevalence rates were mostly related to measurement differences, not response rate (a proxy for selection bias), when studies were framed explicitly as regarding violence (Simmons \& Swahnberg, 2019). 


\section{Framing Effects as an Important Methodological Issue in Sexual Violence Research}

Framing effects can potentially explain methodological issues that have been identified in research as framing can influence whether an individual decides to participate, and once in the study, how they may respond to survey questions (Galesic \& Tournageau, 2007). There is wide variation in previous estimates of the prevalence rates and predictors of sexual violence (Bouffard \& Goodson, 2017; Peterson et al., 2010). For example, Peterson et al. (2010) found that somewhere between $2 \%-73 \%$ of college men experience sexual violence victimization. Bouffard and Goodson (2017) found that masculinity was related to some forms of sexual violence perpetration but not others. Secondly, although the field of sexual violence research is growing rapidly (McCauley et al., 2019), we still see disparities in representation, such as male victimization (Choudhary et al., 2010) and the experiences of historically marginalized people (McCauley et al., 2019). Finally, the field is still vastly underfunded compared to the effects of sexual violence on public health (Waechter \& Ma, 2015). Understanding framing effects may help resolve these issues and indeed, have already impacted needed large-scale violence research. National surveys on crime tend to find lower rates of sexual victimization than those studying health, despite similar sampling frames and items (Kruttschnitt et al., 2014). Thus, understanding the exact nature of framing effects is important for planning future research to ensure that studies are inclusive and equitable - especially when studies can influence policy.

\section{Mechanisms of Framing}

Framing is hypothesized to affect participant responses in three possible ways (Galesic \& Tourangeau, 2007). One way is a response bias (i.e., the cooperative norm), in which participants wish to assist researchers and therefore interpret survey questions in ways that they believe are consistent with what the researcher is attempting to find. Secondly, framing can provide judgmental contrasts, providing participants with an exemplar or "anchor" to judge their own experiences against; incidents inconsistent with that exemplar may not be reported. Finally, framing effects can influence responding via priming memory. In other words, the study's framing may activate associations, and therefore, memories the individual perceives as related, thus "priming" them to remember those topics more or less easily (Ross \& Wang, 2010; Mace et al., 2019). For example, participants in the male-on-female violence condition in Kivirouri et al. (2012) may have been able to effortlessly access memories consistent with this framing via easier semantic priming (the meaning is easily accessible) and autobiographical memory retrieval (recalling their own experiences) mechanisms, thus responding differently than in other contexts (Mace et al., 2019). This is the suggested mechanism for why "crime" surveys under-estimate violence. Due to stereotypes and myths about violence that discourage individuals from considering their experiences as crimes, their memories of these events may not be associated with "crime", making it more difficult to retrieve these memories with a crime-based cue (Kruttschnitt et al., 2014; Regan, 2008). To wit, a study about "personal safety" increases reporting of intimate partner violence compared to one about "crime" (Regan, 2008), suggesting that these increased reports are accurate and that the mechanisms of memory retrieval are responsible for differences.

\section{Prior Research on Framing Effects in Violence Research}

Kivivuori et al. (2012) recruited 3,194 participants across Finland for a national survey study on violence with four study conditions: no framing, female-to-male, male-to-female, female-to-male. Framing effects were strongest intimate partner violence and gender; women reported more violence in the maleon-female condition, and men reported less violence in the male-on-male condition. There were no effects for sexual violence. However, this study did not use behaviorally specific items to assess sexual violence, which result in more accurate and higher rates of victimization than using broad items (Cook et al., 2011). 
Similarly, Galesic and Tourangeau (2007) collected data on sexual harassment in a study advertised as either about "Sexual Harassment" sponsored by a feminist group or "Work Atmosphere" sponsored by the "Work Environment Institute." Finding that women were more likely to report sexual harassment experiences in the sexual harassment condition. At the national level, Kruttschnitt et al. (2014) compared the prevalence rates of national surveys that collected information regarding sexual violence: The National Crime Victimization Study (NCVS), The National Women's Study (NWS), and the Uniform Crime Report (UCR). The NWS and UCR consistently reported levels of sexual victimization five times greater than the NCVS.

Finally, framing effects can activate stereotypes or myths regarding sexual violence, particularly rape (Littleton et al., 2006). American culture tends to promote attitudes and beliefs that blame victims and diminish the perpetrator's responsibility (Dworkin \& Weaver, 2020; Johnson \& Johnson, 2017). An example of the deep stigma associated with rape, is the construct of rape acknowledgment, defined in part by the internalization of stigma. Rape acknowledgment is whether a person who experiences rape victimization labels their experience as rape (Koss, 1985), rather than using a minimizing term such as "miscommunication" (Littleton et al., 2007). Most people who experience rape victimization do not call it rape (on average, 60\% - Wilson \& Miller, 2016); thus, recruiting self-identified "rape victims" introduces selection bias that varies systematically by gender and sexual orientation (Anderson et al., 2017a; Artime et al., 2014). Thus, framing a study to recruit "rape victims" would incur self-selection bias and alter study outcomes as acknowledged rape victims often report different risk profiles and health outcomes (Littleton et al., 2006; Littleton et al., 2009).

\section{Current Study}

The current study used a quasi-experimental design to compare the rates of reported sexual victimization and perpetration in college students in each of four study conditions: health, crime, alcohol, or sexual assault. The first three frames were suggested in Koss et al. (2007), and the final frame, "sexual assault", was chosen per Campbell et al. (2019)'s suggestions on trauma-informed research. We examined reports of sexual violence and related risk factors that may be influenced by the frames chosen. Finally, we investigated how gender, sexuality, race, and ethnicity may have intersected with framing consistent with the many well-documented demographic differences in the experience of sexual violence (McCauley et al., 2019).

We chose a quasi-experimental design for this initial investigation into framing effects to maximize ecology validity. Quasi-experimental designs are often recommended to establish causal inference when ethical, operational, and/or political reasons prohibit the use of a full experimental design (Bärnighausen et al., 2017). With our potential participants being recruited from a subject pool, they can choose from multiples studies and have the option to participate or not. Further, research indicates that giving participants the choice of topic increases self-disclosure of sensitive personal information (Catania et al., 1996; Rohrberg \& Sousa-Poza, 1976). We also suggest that prioritizing participant choice would be important in the study of rape, given the centrality of a lack of consent in rape as does Campbell et al., (2019). A true experimental approach would randomly assign participants to one of the four conditions (health, crime, alcohol, or sexual assault) and would eliminate participants' choice because a true informed consent process would invariably contain framing in some manner.

The following hypotheses are based on semantic priming and memory retrieval as the primary mechanisms behind the effects of framing (Ross \& Wang, 2010; Mace et al., 2019).

Hypothesis 1: Reported rates of sexual victimization will be higher in the sexual assault, health, and alcohol conditions than in crime condition. 
Hypothesis 2: More severe reports of sexual victimization (rape and acknowledgment of rape) will be reported in the sexual assault (SA) condition than in the other conditions.

Hypothesis 3: Reported rates of sexual perpetration will be higher in the Alcohol condition than in the other conditions, consistent with the greater use of alcohol among those who perpetrate sexual violence (Abbey et al., 2014). Many cases of college sexual violence involve alcohol (Abbey, 2002). The alcohol condition will likely prime participants' memory for alcohol-related events, thus facilitating higher rates of retrieval and reporting of alcohol-related sexual perpetration (Ross \& Wang, 2010; Mace et al., 2019).

Hypothesis 4: Attitudes and behaviors (rape myth acceptance, alcohol use, health, fear of crime) congruent with the study frame will be higher in the congruent condition compared to other conditions. For example, treatment utilization will be higher in the health condition, while alcohol expectancies and consumption will be higher in the alcohol condition, et cetera.

\section{Participants}

\section{Method}

Seven-hundred and ninety-two college students were recruited for participation from a large, public Midwestern University (72.9\% female); 230 participants chose the alcohol condition, 179 the crime condition, 199 the health condition, and 174 the sexual assault condition. Data from ten participants were removed because they either did not complete $80 \%$ of the study $(n=2)$; did not complete at least one item on the primary outcome measures (sexual violence questionnaires, $\mathrm{n}=5$ ); their results indicated a response set bias $(\mathrm{n}=1)$, or were not 18 years of age $(\mathrm{n}=2)$. The final sample consisted of 782 participants $(72.4 \%$ female, 26.2\% male, 1.4\% genderqueer/other) aged 18 years or older (Mage =19.65, SD = 6.25). Participants were mostly heterosexual (83.5\%) and White (81.6\%); 13.2\% identified as African American, 3.1\% as Asian/Asian American, $0.8 \%$ as Native American, and $4.9 \%$ as Hispanic or Latina/o.

\section{Measures}

\section{Questionnaires Assessing Sexual Violence}

The Sexual Experiences Survey-Short Form Victimization. The Sexual Experiences Survey - Short Form Victimization (SES-SFV; Koss et al., 2007) consists of behaviorally specific items that combine a description of a sexual behavior (e.g., vaginal penetration)followed by five tactics that describe the means that were used to coerce the sexual behavior (e.g., verbal pressure, verbal coercion, alcohol incapacitation, threats of force, physical force). Modifications to the frequency response scale, additional items, and order randomization were made to allow for consistency among the SES-SFV and other surveys administered, such as The Revised Conflict Tactics Scales (CTS2; Straus et al., 1996) and consistent with advancements in measurement science since the measure was published in 2007 (Dietz \& Jasinski, 2007). Each item was rated on a frequency response scale representing the number of times the behavior was experienced: 0,1 , $2-5,6-9,10+$ times. Because items are specific to a sexual behavior, participants without vaginas were instructed to skip the two items that assess vaginal penetration, resulting in a differential number of items. We added four items that assessed forced penetration, wherein a person is forced to penetrate another person's body (Anderson et al., 2020). Because each item is compound and items were added, the version of the SES-SFV used contained 8-10 sexual behavior stems crossed by five tactic sub-stems for a total of 40-50 items. Rape acknowledgment was assessed using the item, "Have you ever been raped?" placed after the behaviorally specific items. Items were administered in a randomized order. Prior research has demonstrated good evidence of validity; responses to SES-SFV items are correlated with measures of psychological distress (Johnson et al., 2017). Research also suggests good to adequate test-retest reliability for the SES-SFV (Anderson et al., 2018; Johnson et al., 2017). 
The Tactic-First Sexual Experiences Survey-Short Form Perpetration. The Tactic-First Sexual Experiences Survey - Short Form Perpetration (T-SES; Abbey et al., 2005; Koss et al., 2007) was designed to mirror the SES-SFV. We used the term T-SES not to legitimize our questionnaire as an official variant of the SES but rather for simplicity. This version uses tactics as the stem for items (Abbey et al., 2005) rather than descriptions of a sexual behavior followed by tactics. An example item is, "Have you ever told lies or made promises to new were untrue in order to: make them have anal sex with you." This version includes additional tactics compared to prior versions as it contains tactics related to substance use incapacitation and verbal coercion. We made a number of modifications to the questionnaire as published in 2005, reflecting advances in the science of sexual violence measurement since the tactic-first SES was first introduced. We added items regarding pressuring someone to use substances, multiple perpetrator attacks, assessed physical force threats, and use of physical force in two items rather than one. Similar to the SESSFV used in this study, we added items that assessed forced penetration and administered items in a randomized order. The T-SES measures perpetration; all 70 (10 tactics X 7 sexual behaviors) items are administered regardless of sex/gender and on the same frequency response scale as the SES-SFV. T-SES scores are correlated with risk factors for sexual perpetration like alcohol consumption and hostile masculinity and at similar levels to the unaltered SES-Short Form perpetration (Abbey et al., 2021). The T-SES also shows adequate test-retest reliability with $80 \%$ agreement over a one-week interval (Anderson et al., 2021).

The Revised Conflict Tactics Scales-Sexual Coercion Subscales. The Revised Conflict Tactics Scales (CTS2; Straus et al., 1996) contains a total of fourteen paired items to assess sexual victimization and perpetration in established romantic relationships. Romantic partners were defined as "someone you were in a relationship with, such as a boyfriend or girlfriend." Items assess the frequency with which experiences occurred since age 14 on a scale ranging from: never, once, twice, 3-5 times, 6-10 times, 11-20 times, and 20 or more times. The CTS2-SC has demonstrated good evidence of validity with correlations to other measures of sexual victimization (Anderson et al., 2018) and trait aggression (Anderson et al., 2017b). There is limited evidence of test-retest reliability of the CTS2-SC (Vega \& O'Leary, 2007), but it is often recommended to measure intimate partner sexual violence (Bagwell-Gray et al., 2015).

Childhood Trauma Questionnaire-Sexual Abuse Subscale. The Childhood Trauma Questionnaire (CTQ: Bernstein et al., 2003) contains five items, an example item is, “...made to do sexual things." all items were rated on a five-point frequency response scale from 0 (never true), 2 (sometimes true) the midpoint, and 4 (very often true). We used age 14 as the cut-off in this study to ensure reports of sexual victimization were not repeated on the SES-SFV. The CTQ has demonstrated good evidence of validity and reliability in past research (Bernstein et al., 2003) via correlations with therapists' maltreatment severity ratings. Acknowledgment of childhood sexual abuse was assessed by the item, "[I] was sexually abused."

Scoring. On all violence questionnaires, if an item was endorsed at a frequency of 1 or more, violence was considered present and coded. On the SES-SFV, we scored the category of rape and used this with the acknowledgment item to identify those who acknowledged their rape. We calculated continuous scores (e.g. estimated frequency scores) for the SES-SFV and T-SES as an indicator of severity. Still, these numbers do not strictly represent the number of incidents. We used data from the SES-SFV, the CTS2 and the CTQ to compute an "any sexual victimization" variable. We do not report Cronbach's alpha for any of the behavioral measures (including all violence measures) given that these questionnaires do not reflect a latent variable but rather a set of behavioral experiences that may or may not be related and are not caused by any characteristic inherent to participants (Hulme, 2007; Koss et al., 2007). 


\section{Attitudinal Correlate Questionnaires}

Rape Myth Acceptance. The Illinois Rape Myth Acceptance Scale (Payne et al., 1999) uses 45 items to assess agreement with cultural beliefs that promote stereotypes about rape, such as the idea that women who dress provocatively are "asking for it." Each item, such as "men from nice middle-class homes almost never rape," is rated on a seven-point Likert-type scale from 1 (not at all agree) to 7 (very much agree). Internal consistency was $\alpha=.93$.

Health-Related Quality of Life. Health was evaluated with the Medical Outcomes Study Short-Form 12item Health Survey (SF-12). This questionnaire uses 12 items to assess health via pain, interference of health with daily living activities, and self-perceived health. For this study, only six physical health items were scored. The SF-12 has strong evidence of validity, such as correlations with diagnoses of substance use and number of hospitalizations as well as good reliability, with strong test-retest correlations in the general population (Salyers et al., 2000; Ware et al., 1996). An example item is, "During the past four weeks, how much did pain interfere with your normal work (including work outside the home and housework)?" We used raw sum scoring as recommended by Hagell et al. (2017).

Fear of Crime. Fear of crime was assessed using four items specific to the crimes of sexual assault, mugging, murder, and burglary taken from Dowler (2003). Each item, such as "How often do you worry about being sexually assaulted?" was rated on a four-point Likert-type scale from 1 (never) to 4 (very frequently). These items have demonstrated validity via correlations with neighborhood crime problems (Dowler, 2003), $\alpha=.87$.

Alcohol Expectancies. Alcohol expectancies or people's beliefs about the effects of alcohol on thoughts, feelings, and behaviors were assessed using the self-related alcohol expectancies subscale of the Alcohol Expectancies Regarding Sex, Aggression, and Sexual Vulnerability Questionnaire (Abbey et al., 1999). Thus, the self-expectancies subscale can be further divided into expectancies related to aggression, sexual affect, sexual drive, and vulnerability to coercion. An example sex drive item is, "When I'm drinking alcohol... I feel sexually aroused" was rated on a five-point Likert-type scale from 1 (not at all) to 5 (very much). Validity and reliability of this subscale has been demonstrated in prior research by significant correlations with measures of sexuality and aggression and moderate strength test-retest correlations in a sample of college students (Abbey et al., 1999), $\alpha=.95$.

Social Desirability. The Balanced Inventory of Desirable Responding (BIDR) was used to assess social desirability, the tendency to give positively biased self-reports and impression management (Paulhus, 1991). The BIDR uses 40 items to assess these two dimensions of socially desirable responding, including items such as "I am a completely rational person" (self-positive bias) and "I never swear" (impression management). Participants rated their agreement with each item on a seven-point Likert-type scale from 1 (not true) to 7 (very true). Correlations have demonstrated prior evidence of validity with the MarloweCrowne Social Desirability Scale and reliability demonstrated by strong test-retest correlations $(\mathrm{r} \approx .67)$. A total score was used for this study. Internal consistency was, $\alpha=.82$.

\section{Behavioral Correlate Questionnaires}

Sexual Violence Intervention Program Exposure. To assess whether participants had experienced intervention on the topic of sexual violence, three questions regarding ever receiving self-defense, bystander education, or any other type of sexual violence education, responses to these items were combined for an overall variable, 0 (no) and 1 (yes).

Treatment Utilization. Use of healthcare was assessed using an eight-item questionnaire listing various types of treatment resources offered by licensed professionals such as individual psychotherapy, emergency room visit, physical therapy, et cetera. Two dichotomous variables representing mental and physical health utilization, 0 (no) and 1 (yes), were created. 
Problematic Alcohol Use. The Alcohol Use Disorder Identification Test (AUDIT) was used to screen participants for hazardous drinking. The AUDIT uses ten items to assess the frequency and amount of consumption, as well as some indicators of alcohol use problems such as difficulty stopping drinking and negative consequences of drinking, such as "have you or someone else been injured as a result of your drinking?" The AUDIT is one of the screening measures recommended for use by the National Institutes on Alcohol Abuse and Alcoholism, given its sensitivity across populations (Connors \& Volk, 2004). The AUDIT has demonstrated strong test-retest reliability in primary care patients (Daeppen et al., 2000) and positive correlations with trauma history for validity (Bellis et al., 2018).

\section{Procedures}

Participants were undergraduate psychology students at a large public university in the Midwest during the Spring semester of 2018, who received course credit for their participation. The conditions were advertised as separate studies and presented in randomized order with approximately 40 other studies on Sona. Students were only allowed to choose one "study" to participate in and were automatically disabled from participating in any other study condition. There were no limits on the number of participants who could sign up for any condition though sign-ups were monitored. Study participation was entirely online. In addition to the questionnaires described above, questionnaires assessing healthy personality and sexual behavior (motives, performative behavior) were also administered for a co-occurring research project. The IRB at the large, public university approved the protocol, and data were collected in accordance with national and local ethics guidelines.

\section{Framing}

Framing was accomplished via two avenues: the study title, which all potential participants saw, and the study description, which all potential participants could opt to read. Conditions were advertised as separate studies; "Questionnaires about Alcohol," "Questionnaires about Crime," "Questionnaires about Health," or "Questionnaires about Sexual Assault." Framing was embedded within each "studies" oneparagraph description; all studies on the University Sona site had descriptions. Potential participants could opt to click on the description to learn more about a study before participating. The description for each condition varied based on the order in which constructs were listed. The framing construct for each condition was listed first. For example, the description for the crime condition noted, "...complete questionnaires about their experiences with crime, life experiences (including negative ones), health, and alcohol use..." whereas in the alcohol condition, alcohol use was listed first. Similarly, the main study task for the crime condition was described as "complete a series of questionnaires related to crime in college students"; in other conditions, the word crime was replaced with the equivalent frame construct. Study descriptions were otherwise identical, and all four "studies" were posted in the pool on the same day within minutes of each other.

\section{Data Cleaning}

\section{Results}

Missing data were minimal; nearly all participants ( 98\%) completed at least $80 \%$ of each of the study measures. Little's MCAR (1988) analysis of variables showed that missing data were missing completely at random $(\mathrm{MCAR}), \mathrm{c} 2(265,843, \mathrm{~N}=792)=248,718.21, \mathrm{p}=1.00$. Missing data were assumed to be the modal response (0) for measures of sexual violence. Participants who did not complete at least $80 \%$ of the items on attitudinal or behavioral correlate questionnaires were excluded using pairwise deletion. Scores 
were prorated for participants who skipped between 1-20\% of items on these measures. The modal number of minutes to complete the study was 21.3 , mean was 85.9 with a range from 2.6-7536.2 (5.2 days).

\section{Analytic Plan}

We conducted cross-tabulations, chi-square, one-way ANOVA and Pearson's correlation analyses to ensure that demographic characteristics and socially desirable responding (SDR) measured by the BIDR were equivalent across all conditions and to test for relationships between variables and SDR. We used the same analyses to test hypotheses. Bonferroni corrected p-values were used to establish significance when we conducted multiple comparisons.

\section{Socially Desirable Responding}

We tested whether to include the BIDR in analyses following Tracey (2015) and prior literature (Anderson et al., 2018). SDR typically only presents a bias in certain contexts, when the stakes are high (i.e., employment screening) or when responses are not anonymous; neither condition applies to this study. We found a weak negative correlation between the BIDR and $78 \%$ of our dependent variables (all r's $\leq-.23$ ). However, the likelihood of this bias affecting our findings is low considering that the BIDR mean ( $\mathrm{M}=$ 10.93) was significantly lower than the scale mid-point of $20, t(779)=-41.78, p=<.001$ and BIDR scores did not vary by condition, $\mathrm{F}(3,776)=.01, \mathrm{p}=1.0$, nor were BIDR scores significant when included as a covariate. Thus, we report analyses below without controlling for BIDR scores.

\section{Descriptive Results}

Rate of Recruitment and Characteristics of Participants by Condition. More participants chose the alcohol condition $(n=230)$ than the crime $(n=179)$ or sexual assault conditions $(n=174), \chi 2(1, N=781) \geq 8.55$, ps $\leq .004$. There were no differences in the distribution of participants by gender, race, or ethnic identity across conditions. There were some differences in the rate of recruitment. Participants were recruited for ten weeks. More participants chose the sexual assault condition during week one than the health condition, $\chi 2=8.54, \mathrm{p}=.008$. More participants chose the alcohol condition during week four than the sexual assault condition $\chi 2=7.95, \mathrm{p}=.008$.

Victimization and perpetration. Including all three measures (SES-SFV, CTS2, CTQ), the overall rate of lifetime sexual victimization (childhood, adolescence, and adult) was $56.5 \%(n=442)$, or $61.0 \%(n=345)$ of women, and $42.9 \%(n=88)$ of men. The lifetime prevalence rate of adolescent/adult sexual perpetration identified by the T-SES or the CTS2-SC was $29.5 \%$ of the entire sample $(n=231)$, or $27.6 \%(n=156)$ of women, and $36.1 \%(n=74)$ of men.

\section{Sexual Victimization Results}

Hypothesis I: Reported rates of sexual violence (as measured by SES-SFV, CTS2, CTQ) will be higher in sexual assault, health, and alcohol conditions than in crime condition. Cross-tabulations and chi-square analyses revealed that reported rates of SV did not differ statistically across conditions, on measures of adult victimization, SES-SFV, $\chi 2(3, \mathrm{~N}=782)=6.87, \mathrm{p}=.076, \mathrm{CTS} 2, \chi 2(3, \mathrm{~N}=782)=1.56, \mathrm{p}=.668$. However, rates of childhood sexual abuse significantly differed, $\chi 2(3, \mathrm{~N}=782)=12.94, \mathrm{p}=.005$. Specifically, Fisher's Exact $2 \times 2$ comparisons revealed that childhood sexual abuse was significantly higher in the SA condition $33.6 \%,(n=40)$, compared to the Crime condition $18.5 \%(n=22), p<.001$, the Health condition, $17.6 \%,(\mathrm{n}=21), \mathrm{p}=.01$, and the Alcohol condition $15.7 \%,(\mathrm{n}=36), \mathrm{p}=.039$. The comparisons of the Alcohol and Health conditions to the crime condition did not statistically differ, ps $>.05$, see Table 1 . 
Hypothesis 2: More severe reports of sexual victimization (rape, sexual victimization frequency, and acknowledgment) will be collected in the sexual assault (SA) condition than in the other conditions. There was a significant difference in reports of rape by condition, $\chi 2(3, N=782)=8.12, p=.04$. Follow-up Fisher's exact $2 \times 2$ planned comparisons using Bonferroni adjusted alpha levels of .017 per test (.05/3) indicated significantly more reports of rape in the SA condition than the Health condition, $p=.007$. Further examining this finding for demographic differences, results indicate that there were significantly more reports of rape for White participants, regardless of gender, in the SA condition than the Health condition, $\mathrm{p}=$ .001 . Descriptively, $33.9 \%$ of participants reported rape in the SA condition, $30.2 \%$ in the Crime condition, $27.8 \%$ in the Alcohol condition, and $21.1 \%$ of the Health condition participants, see Table 1 . In other words, 1.6x more participants reported rape in the SA condition than the health condition (a difference of 12.8 percentage points).

A one-way ANOVA examining the frequency of sexual victimization (i.e., the estimated total number of sexual violence victimization experiences) by condition revealed that the number of acts of sexual victimization experiences differed significantly by condition, using Welch's $F(3,413.78)=2.66, p=.05$, $\eta p 2$ $=.008$. Planned contrasts revealed that the mean number of estimated victimization experiences in the SA condition was significantly higher than in the Health condition, $\mathrm{t}(289.84)=-2.41, \mathrm{p}=.017, \mathrm{np} 2=.007$, but not the Alcohol or Crime conditions. The mean number of estimated victimizations reported in the SA condition was 11.35 , whereas only 5.44 estimated victimizations were reported in the Health condition (see Table 1).

There were no gender differences in acknowledgment, but there were differences in sexual identity. Specifically, people who identified as bisexual reported more acknowledged rape in adolescent/adulthood and acknowledged childhood sexual abuse in the Sexual Assault condition compared to the Health condition (see Table 1).

Hypothesis 3: Reported rates of sexual perpetration (SP; as measured by T-SES-SFP and the CTS2-SC) will be higher in the Alcohol condition than in the other conditions. Chi-square analyses revealed that there were no differences in the reported rates of sexual violence perpetration on either measure across conditions, $\chi 2(3, \mathrm{~N}=782) \leq 3.05, \mathrm{p} \geq .38$, nor when considering just reports of rape on the T-SES-SFP, $\chi 2(3, \mathrm{~N}$ $=782)=.68, \mathrm{p}=.88$, nor T-SES-SFP frequency scores, $\mathrm{F}(3,776)=1.25, \mathrm{p}=.29, \mathrm{np} 2=.005$.

\section{Behavioral and Attitudinal Correlates Results, Hypotheses 4-8}

None of the hypotheses were supported. All analyses were non-significant with very small effect sizes, see Table 2 .

\section{Discussion}

This study aimed to examine how title-based framing effects might affect self-reported sexual violence outcomes and associated risk factors. Even though the current study used a quasi-experimental design, this is one of the few studies to examine this methodological issue, which is important for advancing research on sexual violence. We found that framing did affect reported rates of sexual violence victimization but no other constructs. This is critical information for study planning and interpreting results.

\section{Victimization Findings}

We found more reports of childhood sexual abuse, rape, a higher frequency of sexual victimization, and more reports of acknowledged rape and childhood sexual abuse for bisexual people in the sexual assault condition $(\mathrm{H} 2)$. However, the effects of framing were complex; we did not find any differences in the reported prevalence rates of sexual violence victimization in adolescent/adulthood on the SES-SFV or the 
CTS2, inconsistent with hypotheses (H1). It is further notable that our finding regarding reports of rape was specific to White participants, regardless of gender, and acknowledgment was increased only for bisexual participants.

Generally, our findings are consistent with concerns raised by Kruttschnitt et al. (2014) - that studies about "crime" tend to find lower prevalence rates of sexual violence. We suggest that the title-based framing (i.e., "Study about Sexual Assault') activates semantic memory that then primes autobiographical memory retrieval (Mace et al., 2019); thus, facilitating more accurate recall and greater rates of self-reporting. It is also possible that the differences in frequency of reported victimization between conditions could represent an inaccurate estimate related to the influence of the availability heuristic; our participants were college students who likely experienced relative events recently in memory. The availability heuristic suggests such that immediate examples bias memory recall to perceive events as occurring more often (Tversky \& Kahneman, 1973). However, we have no reason to think participants' reports were inaccurate given rates were generally consistent with the literature (Muehlenhard et al., 2017). Thus, it is unclear whether these differences between conditions reflect the suppression of reporting in certain conditions or increased reporting in the sexual assault condition.

\section{Perpetration, Attitudinal, and Behavioral Correlate Findings}

There were no significant differences in the reported rates of sexual perpetration or related risk factors (contrary to H3). Possibly there were floor effects related to the low levels of fear of crime, exposure to sexual assault education/prevention program, and problems in accessing healthcare $(\mathrm{H} 4)$. Alternatively, perhaps we did not assess the type of correlates affected by framing effects, although correlates were based on prior literature. It may be that framing effects are stronger for more stigmatized topics/behaviors - based on the victimization findings, one could argue that framing is necessary to produce accurate reports. It is possible that the sexual assault condition represents the most accurate data.

\section{Future Research and Limitations}

We recommend future research on framing effects and sexual victimization, given that we found differences in the degree and some rates of sexual victimization. We also recommend further research on this topic in general, given how much cultural variability there can be. For example, in a predominantly observant Muslim community, a study about alcohol would be perceived quite differently. Future studies might take a purely experimental approach by advertising a study more generally than randomly assigning participants to conditions that receive different instructions or informed consent. Other frames to investigate might be "Relationships" or "Sexual Behavior" as ethically speaking, these are transparent titles.

Secondly, further research is important to rule out self-selection issues fully. Participants in the sexual assault condition may be different. For example, we found no gender differences in rape acknowledgment, which is contrary to prior literature suggesting our sample may be unusual in some way (Anderson et al., 2018; Wilson \& Miller, 2016). Feeling comfortable to disclose in the sexual assault condition may have only been experienced by White individuals, as this effect was racially specific. Considering $13 \%(n=102)$ of the sample were Black Americans, it is important to consider this community's generational trauma surrounding abuse in scientific research and how that impacts individuals today. Perhaps Black Americans in our study were less inclined to disclose due to the history of mistreatment and discrimination experienced by individuals of racial minorities in research within the United States, such as the Tuskegee study for but one example (Alsan et al., 2020). Building trust and partnerships among Black American communities and researchers can and has been done - working with community agencies, collaborating with community advisory boards, and mixed methods designs all provide opportunities to develop relationships and empower marginalized communities (Wyatt, 1992; Lindquist et al., 2016). Explicitly acknowledging the 
challenge of the work, the historical failures, current intersectional challenges, and actively seeking collaboration and feedback can all facilitate better, more inclusive research.

\section{Clinical and Policy Implications}

It appears that in clinical work, practitioners can be fairly straightforward - there is little need to minimize or hide the titles of questionnaires. Our findings suggest that, for researchers, the decision is regarding which framing effects to incorporate; it remains to be seen whether any frame will be neutral. Framing effects and framing choices will be highly variable based on the study's goals. For example, studies needing fast recruitment may choose the alcohol frame, which was the most popular in our study. In general, our findings suggest that sexual assault framing will increase statistical power by increasing reported prevalence rates for certain characteristics - a gain for most research projects. Our findings suggest that common frames such as alcohol and health may not be as "neutral" or subtle as previously thought, given the findings associated with these conditions were more similar to the crime condition than the sexual assault condition. Considering the cultural norms around rape, and our findings, framing may actually be necessary to promote accurate memory retrieval and that much research under-estimates sexual victimization. Interestingly, we found no effects for sexual perpetration. The frames in this study may not have been powerful enough to overcome unintentional underreporting associated with sexual perpetration; alternatively, framing may not be as important for perpetration as it is for victimization. The impact of framing on findings is particularly important when considering resource allocation, as some framing may underestimate sexual violence and therefore suggest a misalignment of resources.

\section{Conclusion}

Our findings suggest that framing effects, even quite simple ones based on study titles, affect study findings in sexual victimization research. Common frames like alcohol, health, and crime may under-estimate sexual victimization and are not "neutral" ways to frame sexual violence. Framing may be particularly important for historically marginalized individuals as we found differential effects for bisexual women and Black women in our study. Unexpectedly, our findings suggest that the frames tested here do not affect the self-report of perpetration or related correlates. Understanding framing important for continuing to grow the field of sexual violence and the ethical duty to promote participants' autonomy while, collecting meaningful data that values and respects participants' time and effort. Future research should seek to replicate these findings, further investigate this and related methodological issues to facilitate the advancement of sexual violence research in an inclusive and equitable manner.

\section{Declaration of Conflicting Interests}

We have no conflict of interest to disclose.

\section{Funding}

Dr. Anderson's work was supported by a grant from the National Institute on Alcohol Abuse and Alcoholism (5K01AA02664302/-03). The content is solely the responsibility of the authors and does not necessarily represent the official views of the funding agency. 


\section{ORCID iD}

\section{RaeAnn E. Anderson (D) https://orcid.org/0000-0001-9938-0717}

\section{Supplemental Material}

Supplemental material for this article is available online.

\section{References}

Abbey, A., McAuslan, P., Ross, L. T., \& Zawacki, T. (1999). Alcohol expectancies regarding sex, aggression, and sexual vulnerability: Reliability and validity assessment. Psychology of Addictive Behaviors, 13(3), 174-182.

Abbey, A. (2002). Alcohol-related sexual assault: A common problem among college students. Journal of Studies on Alcohol, supplement, (14), 118-128.

Abbey, A., Helmers, B. R., Jilani, Z., McDaniel, M. C., \& Benbouriche, M. (2021). Assessment of men's sexual aggression against women: An experimental comparison of thre versions of the SExual Experiences Survey. Psychology of Violence, in press.

Abbey, A., Parkhill, M. R., \& Koss, M. P. (2005). The effects of frame of reference on responses to questions about sexual assault victimization and perpetration. Psychology of Women Quarterly, 29(4), 364-373.

Abbey, A., Wegner, R., Woerner, J., Pegram, S. E., \& Pierce, J. (2014). Review of survey and experimental research that examines the relationship between alcohol consumption and men's sexual aggression perpetration. Trauma, Violence, \& Abuse, 15(4), 265-282. https://doi.org/10.1177/1524838014521031

Alsan, M., Wanamaker, M., \& Hardeman, R. R. (2020). The Tuskegee Study of untreated syphilis: A case study in peripheral trauma with implications for health professionals. Journal of general internal medicine, 35(1), 322-325.

Anderson, R. E., Wandrey, R. L., Klossner, S. C., Cahill, S. P., \& Delahanty, D. L. (2017a). Sexual minority status and interpersonal victimization in college men. Psychology of Sexual Orientation and Gender Diversity. https://doi.org/10.1037/sgd0000204

Anderson, R. E., Cahill, S. P., \& Delahanty, D. L. (2017b). Initial Evidence for the Reliability and Validity of the Sexual Experiences Survey-Short Form Perpetration (SES-SFP) in College Men. Journal of Aggression, Maltreatment and Trauma, 26(6), 626-643. https://doi.org/10.1080/10926771.2017.1330296

Anderson, R. E., Cahill, S. P., \& Delahanty, D. L. (2018). The psychometric properties of the Sexual Experiences SurveyShort Form Victimization (SES-SFV) and characteristics of sexual victimization experiences in college men. Psychology of Men and Masculinity, 19(1), 25-34. https://doi.org/10.1037/men0000073

Anderson, R. E., Goodman, E. L., \& Thimm, S. S. (2020). The assessment of forced penetration: A necessary and further step toward understanding men's sexual victimization and women's perpetration. Journal of Contemporary Criminal Justice, 36(4), 480-498.

Anderson, R. E., Garcia, M. \& Delahanty, D. L. (2021) Test-retest reliabilities of four tactic-first sexual violence history questionnaires. Psychology of Violence, in press

Artime, T. M., McCallum, E. B., \& Peterson, Z. D. (2014). Men's acknowledgment of their sexual victimization experiences. Psychology of Men \& Masculinity, 15(3), 313-323.

Bagwell-Gray, M. E., Messing, J. T., \& Baldwin-White, A. (2015). Intimate partner sexual violence: A review of terms, definitions, and prevalence. Trauma, Violence, \& Abuse, 16(3), 316-335. https://doi.org/10.1177/1524838014557290

Bärnighausen, T., Tugwell, P., Røttingen, J. A., Shemilt, I., Rockers, P., Geldsetzer, P., ... \& Bor, J. (2017). Quasi-experimental study designs series - paper 4: uses and value. Journal of clinical epidemiology, 89, 21-29.

Basile, K. C., Smith, S., Breiding, M. J., Black, M. C., \& Mahendra, R. (2014). Sexual Violence Surveillance: Uniform Definitions and Recommended Data Elements, Version 2.0. https://www.cdc.gov/violenceprevention/pdf/sv_surveillance_definitionsl-2009-a.pdf

Bernstein, D. P., Stein, J. A., Newcomb, M. D., Walker, E., Pogge, D., Ahluvalia, T., Stokes, J., Handelsman, L., Medrano, M., Desmond, D., \& Zule, W. (2003). Development and validation of a brief screening version of the Childhood Trauma Questionnaire. Child Abuse \& Neglect, 27, 169-190. https://doi.org/10.1016/S0145-2134(02)00541-0

Bouffard, L., \& Goodson, A. (2017). Sexual coercion, sexual aggression, or sexual assault: How measurement impacts our understanding of sexual violence. Journal of aggression, conflict and peace research.

Campbell, R., Goodman-Williams, R., \& Javorka, M. (2019). A trauma-informed approach to sexual violence research ethics and open science. Journal of interpersonal violence, 34(23-24), 4765-4793.

Catania, J. A., Binson, D., Canchola, J., Pollack, L. M., Hauck, W., \& Coates, T. J. (1996). Effects of interviewer gender, interviewer choice, and item wording on responses to questions concerning sexual behavior. Public Opinion Quarterly, 60(3), 345-375. 
Choudhary, E., Coben, J., \& Bossarte, R. M. (2010). Adverse health outcomes, perpetrator characteristics, and sexual violence victimization among US adult males. Journal of interpersonal violence, 25(8), 1523-1541.

Connors, G. J., \& Volk, R. J. (2004). Self-Report Screening for Alcohol Problems Among Amon Adults in Assessing Alcohol Problems: A Guide for Clinicians and Researchers (2nd). https://pubs.niaaa.nih.gov/publications/AssessingAlcohol/index.htm

Cook, S. L., Gidycz, C. A., Koss, M. P., \& Murphy, M. (2011). Emerging issues in the measurement of rape victimization. Violence against women, 17(2), 201-218.

Daeppen, J.-B., Yersin, B., Landry, U., Pecoud, A., \& Decrey, H. (2000). Reliability and validity of the Alcohol use Disorders Identification Test (AUDIT) imbedded within a general health risk screening questionnaire: Results of a survey in 332 primary care patients. Alcoholism: Clinical and Experimental Research, 24(5), 659-665. https://doi.org/10.1111/j.15300277.2000.tb02037.x

Dietz, T. L., \& Jasinski, J. L. (2007). The effect of item order on partner violence reporting: An examination of four versions of the revised Conflict Tactics Scales. Social Science Research, 36(1), 353-373.

Dowler, K. (2003). Media consumption and public attitudes toward crime and justice: The relationships between fear of crime, punitive attitudes, and perceived police effectiveness. Journal of Criminal Justice and Popular Culture, 10(2), $109-126$.

Dworkin, E. R., \& Weaver, T. L. (2020). The impact of sociocultural contexts on mental health following sexual violence: A conceptual model. Psychology of Violence. https://doi.org/10.1037/vio0000350

Galesic, M., \& Tourangeau, R. (2007). What is sexual harassment? It depends on who asks! Framing effects on survey responses. Applied Cognitive Psychology: The Official Journal of the Society for Applied Research in Memory and Cognition, 21(2), 189-202.

Hamby, S. (2017). On defining violence, and why it matters. Psychology of Violence, 7(2), 167-180.

Hagell, P., Westergren, A., \& Årestedt, K. (2017). Beware of the origin of numbers: Standard scoring of the SF-12 and SF36 summary measures distorts measurement and score interpretations. Research in nursing \& health, 40(4), 378-386.

Hulme, P. A. (2007). Psychometric evaluation and comparison of three retrospective, multi-item measures of childhood sexual abuse. Child Abuse and Neglect, 31(8), 853-869. https://doi.org/10.1016/j.chiabu.2007.03.016

Johnson, N. L., \& Johnson, D. M. (2017). An empirical exploration into the measurement of rape culture. Journal of Interpersonal Violence, 088626051773234. https://doi.org/10.1177/0886260517732347

Johnson, S. M., Murphy, M. J., \& Gidycz, C. A. (2017). Reliability and validity of the Sexual Experiences Survey - Short Forms victimization and perpetration. Violence and Victims, 32(1), 78-92. https://doi.org/10.1891/0886-6708.VV-D-1500110

Kennedy, A. C., \& Prock, K. A. (2018). "I Still Feel Like I Am Not Normal": A review of the role of stigma and stigmatization among female survivors of child sexual abuse, sexual assault, and intimate partner violence. Trauma, Violence, and Abuse, 19(5), 512-527. https://doi.org/10.1177/1524838016673601

Kivivuori, J., Sirén, R., \& Danielsson, P. (2012). Gender framing effects in victim surveys. European Jouranl of Criminology, 9(2), 142-158

Koss, M. P. (1985). The hidden rape victim: Personality, attitudinal, and situational characteristics. Psychology of women quarterly, 9(2), 193-212.

Koss, M. P. (1993). Rape: Scope, impact, interventions, and public policy responses. American Psychologist, 48(10), 10621069. https://doi.org/10.1037/0003-066X.48.10.1062

Koss, M. P., Abbey, A., Campbell, R., Cook, S., Norris, J., Testa, M., Ullman, S., West, C., \& White, J. (2007). Revising the SES: A collaborative process to improve assessment of sexual aggression and victimization. Psychology of Women Quarterly, 31(4), 357-370. https://doi.org/10.1111/j.1471-6402.2007.00385.x

Kruttschnitt, C., Kalsbeek, W. D., \& House, C. C. (2014). Estimating the incidence of rape and sexual assault.

Lindquist, C. H., Crosby, C. M., Barrick, K., Krebs, C. P., \& Settles-Reaves, B. (2016). Disclosure of sexual assault experiences among undergraduate women at historically black colleges and universities (HBCUs). Journal of American college health, 64(6), 469-480.

Little, R. J. (1988). A test of missing completely at random for multivariate data with missing values. Journal of the American statistical Association, 83(404), 1198-1202.

Littleton, H. L., Axsom, D., Breitkopf, C. R., \& Berenson, A. (2006). Rape acknowledgment and postassault experiences: How acknowledgment status relates to disclosure, coping, worldview, and reactions received from others. Violence and victims, 21(6), 761-778.

Littleton, H. L., Rhatigan, D. L., \& Axsom, D. (2007). Unacknowledged rape: How much do we know about the hidden rape victim? Journal of Aggression, Maltreatment \& Trauma, 14(4), 57-74. https://doi.org/10.1300/J146v14n04_04

Littleton, H., Axsom, D., \& Grills-Taquechel, A. (2009). Sexual assault victims' acknowledgment status and revictimization risk. Psychology of Women Quarterly, 33(1), 34-42. 
Mace, J. H., McQueen, M. L., Hayslett, K. E., Staley, B. J. A., \& Welch, T. J. (2019). Semantic memories prime autobiographical memories: General implications and implications for everyday autobiographical remembering. Memory \& cognition, 47(2), 299-312.

McCauley, H. L., Campbell, R., Buchanan, N. T., \& Moylan, C. A. (2019). Advancing theory, methods, and dissemination in sexual violence research to build a more equitable future: An intersectional, community-engaged approach. Violence against women, 25(16), 1906-1931.

Muehlenhard, C. L., Peterson, Z. D., Humphreys, T. P., \& Jozkowski, K. N. (2017). Evaluating the one-in-five statistic: Women's risk of sexual assault while in college. In Journal of Sex Research (Vol. 54, Issues 4-5, pp. 549-576). Taylor \& Francis. https://doi.org/10.1080/00224499.2017.1295014

Paulhus, D. L. (1991). Measurement and control of response bias. In . P. Robinson, P. R. Shaver, \& L. S. Wrightsman (Eds.), Measures of personality and social psychological attitudes (pp. 17-59). Academic Press. https://doi.org/10.1016/B9780-12-590241-0.50006-X

Payne, D. L., Lonsway, K. A., \& Fitzgerald, L. F. (1999). Rape myth acceptance: Exploration of its structure and its measurement using the Illinois Rape Myth Acceptance Scale. Journal of Research in Personality, 33(1), 27-68. https://doi.org/10.1006/jrpe.1998.2238

Peterson, Z. D., Voller, E. K., Polusny, M. A., \& Murdoch, M. (2010). Prevalence and consequences of adult sexual assault of men: review of empirical findings and state of the literature. Clinical Psychology Review, 31(1), 1-24. https://doi.org/10.1016/j.cpr.2010.08.006

Regan, K. V. (2008). Framing violence: The effect of survey context and question framing on reported rates of partner violence (Doctoral dissertation, Dept. of Psychology-Simon Fraser University)

Rohrberg, R. G., \& Sousa-Poza, J. F. (1976). Alcohol, field dependence, and dyadic self-disclosure. Psychological Reports, 39(3_suppl), 1151-1161.

Rosenthal, M. N., \& Freyd, J. J. (2018). Sexual violence on campus: No evidence that studies are biased due to self-selection. Dignity: A Journal on Sexual Exploitation and Violence, 3(1), 7.

Ross, M., \& Wang, Q. (2010). Why we remember and what we remember: Culture and autobiographical memory. Perspectives on Psychological Science, 5(4), 401-409.

Ryan, K. M. (2011). The relationship between rape myths and sexual scripts: The social construction of rape. Sex roles, 65(1112), 774-782.

Salyers, M. P., Bosworth, H. B., Swanson, J. W., Lamb-Pagone, J., \& Osher, F. C. (2000). Reliability and validity of the SF12 health survey among people with severe mental illness. Medical care, 1141-1150.

Saunders, D. M., Fisher, W. A., Hewitt, E. C., \& Clayton, J. P. (1985). A method for empirically assessing volunteer selection effects: Recruitment procedures and responses to erotica. Journal of Personality and Social Psychology, 49(6), 1703 1712. https://doi.org/10.1037/0022-3514.49.6.1703

Senn, C. Y., \& Desmarais, S. (2001). Are our recruitment practices for sex studies working across gender? The effect of topic and gender of recruiter on participation rates of university men and women. Journal of Sex Research, 38(2), 111-117.

Simmons, J., \& Swahnberg, K. (2019). Can nonresponse bias and known methodological differences explain the large discrepancies in the reported prevalence rate of violence found in Swedish studies?. Plos one, 14(5), e0216451.

Straus, M. A., Hamby, S. L., Boney-McCoy, S., \& Sugarman, D. B. (1996). The revised Conflict Tactics Scales (CTS2) development and preliminary psychometric data. Journal of family issues, 17(3), 283-316.

Tracey, T. J. G. (2015). A note on socially desirable responding. Journal of Counseling Psychology. https://doi.org/10.1037/cou0000135

Tversky, A., \& Kahneman, D. (1973). Judgment under uncertainty: Heuristics and biases. doi.org/10.21236/ad0767426

Vega, E. M., \& O’Leary, K. D. (2007). Test-retest reliability of the revised Conflict Tactics Scales (CTS2). Journal of Family Violence. https://doi.org/10.1007/s10896-007-9118-7

Waechter, R., \& Ma, V. (2015). Sexual violence in America: Public funding and social priority. American journal of public health, 105(12), 2430-2437.

Ware, J. E., Kosinski, M., \& Keller, S. D. (1996). A 12-item Short-Form Health Survey: Construction of scales and preliminary test of reliability and validity. Care, 34(3), 220-233.

Wilson, L. C., \& Miller, K. E. (2016). Meta-Analysis of the prevalence of unacknowledged rape. Trauma, Violence \& Abuse, 17(2), 149-159. https://doi.org/10.1177/1524838015576391

Wolitzky-Taylor, K. B., Resnick, H. S., McCauley, J. L., Amstadter, A. B., Kilpatrick, D. G., \& Ruggiero, K. J. (2011). Is reporting of rape on the rise? A comparison of women with reported versus unreported rape experiences in the National Women's Study-Replication. Journal of Interpersonal Violence, 26(4), 807-832. https://doi.org/10.1177/0886260510365869

Wyatt, G. E. (1992). The sociocultural context of African American and White American women's rape. Journal of Social Issues, 48(1), 77-91. 
Table I. Findings for Differences in Sexual Victimization Findings across Conditions

\begin{tabular}{|c|c|c|c|c|c|c|c|}
\hline $\begin{array}{l}\text { Condi- } \\
\text { tion }\end{array}$ & $\begin{array}{l}\text { \% report- } \\
\text { ing any } \\
\text { victim }^{\circ} \\
(n=442)\end{array}$ & $\begin{array}{l}\text { \% report- } \\
\text { ing CSA } \\
(n=119)\end{array}$ & $\begin{array}{l}\% \text { re- } \\
\text { porting } \\
\text { rape } \\
(n=219)\end{array}$ & $\begin{array}{c}\mathrm{M} \# \\
\text { incidents }\end{array}$ & $\begin{array}{c}\text { SD } \\
\text { incidents }\end{array}$ & $\begin{array}{l}\% \text { bisexual } \\
\text { acknowl- } \\
\text { edged, child } \\
(n=48)\end{array}$ & $\begin{array}{l}\% \text { bisexual } \\
\text { acknowl- } \\
\text { edged, adult* } \\
(n=51)\end{array}$ \\
\hline Alcohol & 51.8 & $15.7^{\mathrm{c}}$ & $27.8^{b}$ & 10.19 & 27.72 & 23.1 & 33.3 \\
\hline SA & 63.2 & $33.6^{\mathrm{abc}}$ & $33.9^{\mathrm{a}}$ & $11.35^{\mathrm{a}}$ & $27.52^{\mathrm{a}}$ & $33.3^{\mathrm{a}}$ & $46.2^{\mathrm{a}}$ \\
\hline Crime & 58.7 & $18.5^{\mathrm{a}}$ & 30.2 & 8.34 & 24.46 & 13.3 & 27.3 \\
\hline Health & 50.8 & $17.6^{\mathrm{b}}$ & $21.1^{\mathrm{ab}}$ & $5.44^{\mathrm{a}}$ & $18.05^{\mathrm{a}}$ & $0.0^{\mathrm{a}}$ & $0.0^{\mathrm{a}}$ \\
\hline
\end{tabular}

Note: $\mathrm{n}$ 's listed in column headers are the total $\mathrm{n}$ for that category. Superscripts indicate statistical differences between the paired comparisons. ${ }^{\circ}$ victimization in childhood, adolescent/adulthood, or from an intimate partner. $\mathrm{CSA}=$ childhood sexual abuse, $*$ abbreviated for space, adolescent/adulthood, $\mathrm{SA}=\mathrm{Sex}-$ ual Assault.

Table 2. Effect of Condition on Attitudinal and Behavioral Correlates of Sexual Violence

\begin{tabular}{llccc}
\hline \multicolumn{1}{c}{ Construct/Variable } & $\begin{array}{l}\text { Sample } \mathrm{M}, S D \text { or } \\
n, \text { prevalence }\end{array}$ & $\mathrm{F}(3,777-782)$ & $p$ & $\eta_{\text {partial }}^{2}$ \\
\hline $\begin{array}{l}\text { rape myth acceptance } \\
\text { prior participant in SA pro- }\end{array}$ & $\begin{array}{l}72.31,30.80 \\
\text { grams }\end{array}$ & .36 & .78 & .001 \\
perceived physical health & $17.43,2.21$ & 2.39 & .50 & $\mathrm{n} / \mathrm{a}$ \\
$\begin{array}{l}\text { treatment utilization } \\
\text { fear of crime }\end{array}$ & $4.54,2.64$ & .62 & .61 & .002 \\
total alcohol consumption & $7.49,3.13$ & .34 & .80 & .001 \\
$\begin{array}{l}\text { alcohol consumption-clinical } \\
\text { risk }\end{array}$ & $5.44,4.89$ & 1.68 & .17 & .006 \\
alcohol expectancies & $n=201,25.80 \%$ & 1.8 & .62 & .002 \\
& $10.79,5.64 / 18.04,7.14^{*}$ & $\leq 2.21$ & .60 & $\mathrm{n} / \mathrm{a}$ \\
\hline
\end{tabular}

Note. n/a, this statistic is not applicable to chi-square analyses. For participation in SA programs and alcohol clinical risk indicator prevalence rates are reported. *four expectancies subscales were assessed, the highest and lowest are listed 